УДК 332.146 .2

РАЗВИТИЕ ТОСЭР В ГРАНИЦАХ СТАРОПРОМЫШЛЕННЫХ МОНОГОРОДОВ

Алексей Д. Ризов

${ }^{1}$ Акиионерное общество «Чусовской металлургический завод», 618200, Россия, г. Чусовой, ул. Трудовая, 13

${ }^{2}$ Земское собрание Чусовского муниципального района, 618204, Россия, г. Чусовой, ул. Сивкова, 8 Б

@aleksejrizov@rambler.ru

Поступила в редакиию 22.01.2018. Принята к печати 27.03.2018.

Ключевые слова: старопромышленный моногород, монопродуктовый регион, инновационная стратегия, территория опережающего социально-экономического развития (ТОСЭР).

\begin{abstract}
Аннотация: Предметом данной работы являются старопромышленные моногорода и монопродуктовые регионы Пермского края. Цель - разработка стратегических подходов к решению научно-практической проблемы реализации заявленных перспектив ТОСЭР, созданных в границах монопродуктовых регионов. Основу методологии работы составили: волновая теория (Н. Д. Кондратьев), концепция инновационной активности (Г. Менш), кластеров (М. Портер), тройной спирали и др. Результатом работы является Концепция ТОСЭР, созданной в границах старопромышленного монопродуктового региона. Ее основа - Концепция инновационного развития старопромышленных моногородов [1]. Областью применения результатов работы являются монопродуктовые регионы, планирующие подать заявку для приобретения статуса ТОСЭР. Также область применения результатов работы включает монопродуктовые регионы, уже имеющие статус ТОСЭР.

Выводом является следующее заключение автора: подаче заявки должна предшествовать работа по выработке научно-обоснованной стратегии развития монопродуктового региона, которая получила бы поддержку населения в ходе широких общественных обсуждений, организованных органами власти региона.
\end{abstract}

Для цитирования: Ризов А. Д. Развитие ТОСЭР в границах старопромышленных моногородов // Вестник Кемеровского государственного университета. Серия: Политические, социологические и экономические науки. 2018. № 2. C. 133-138. DOI:10.21603/2500-3372-2018-2-133-138.

В Пермском крае расположены 297 населенных пунктов с 150 тыс. жителей. Из городских округов края десять отнесены к монопродуктовым муниципальным образованиям одного из двух типов. К первому - первой категории монопрофильных муниципальных образований Российской Федерации - относятся города Нытва, Очер, Красновишерск, Чусовой и поселки городского типа Теплая Гора, Уральский. Это монопродуктовые территории, в которых социально-экономическая ситуация признана наиболее сложной. Остальные монопрофильные муниципальные образования относятся ко второму типу - второй категории монопродуктовых территорий - города Горнозаводск и Александровск, поселок городского типа Пашия, поселок Юго-Камский. В них существуют риски ухудшения показателей социально-экономического развития. Следует отметить, что в Пермском крае количество моногородов является достаточно большим, и $60 \%$ из них относятся к монопродуктовым территориям первой категории [2].

В условиях санкций, снижения уровня международной торговли, обмена товарами, услугами, технологиями с западно-европейскими странами, оттока инвестиций, резкого снижения межкультурных коммуникаций, трудности испытывают не только моногорода, но и целые отрасли, включая передовые (например в оборонной сфере, сырьевых отраслях). С учетом того, что программа поддержки моногородов в период финансово-экономического кризиса 2008-2010 гг. не привела к ожидаемым результатам диверсификации экономики моногородов, а свелась к временной поддержке градообразующих предприятий и решению проблемы занятости населения, сдерживанию роста безработицы. Отметим, что в конце 2013 г. уровень безработицы превышал 18 \% в 15 \% моногородов РФ.

С публикацией в 2014 г. Федерального закона № 473 от 29.12.2014 г. «О территориях опережающего социально-экономического развития в Российской Федерации» появилась основа для дальнейшей разработки специальных инструментов государственной поддержки монопродуктовых территорий РФ. Само понятие «территория опережающего социально-экономического развития» (ТОСЭР) законодателем интерпретировано как территория, обладающая особым правовым режимом осуществления предпринимательской и иной деятельности для создания благоприятных условий по привлечению инвестиций, обеспечению ускоренного социально-экономического развития и созданию комфортных условий для обеспечения жизнедеятельности населения [3]. Экономическая сущность ТОСЭР - диверсификация экономики монопродуктовых территорий, что коррелирует с сущностью «КИП» (комплексного инвестиционного плана социально-экономического развития моногорода), целью которого было создание якорных производств с необходимым количеством рабочих мест. Отметим, что в период 2010-2012 гг. государство поддержало 
более пятидесяти моногородов, оказав им финансовую и иную помощь в рамках программ развития моногородов (КИП). Автором были выявлены стратегии, применяемые градообразующими предприятиями Пермского края и монопродуктовыми территориями их расположения. Для моногородов это были стратегия диверсификации экономики, стратегия формирования и развития кластерных образований [4]. Названные стратегии выбираются как модель, а содержательная часть - интерпретация модели, связанная с конкретизацией входящих в нее элементов.

Анализ поданных заявок на получение статуса ТОСЭР моногородами Пермского края привел к заключению, что предусмотренные законом о ТОСЭР для моногородов виды экономической деятельности, предложенные в заявках, формально отвечают требованиям о диверсификации экономики городов данного типа. Более того, например, в случае МО «Чусовское городское поселение» представлено три блока из 22 видов экономической деятельности, распределенных по таким отраслям, как сельское хозяйство, легкая промышленность, полиграфия, индустрия развлечений и отдыха, деревообрабатывающая отрасль, производство электронной техники, производство и ремонт автотранспортных средств и оборудования. Остальные виды экономической деятельности связаны с отраслями градообразующего предприятия - металлургией, машиностроением, химической промышленностью и электрооборудованием. Укажем, что данные производства ориентированы на внутреннего, регионального потребителя произведенной продукции. Возможные межрегиональные поставки увеличат объем РВП. Рост ВВП за счет экспорта могут обеспечить производства, связанные с природными ресурсами края (полезные ископаемые, лесные ресурсы). Они, однако, не относятся ни к высокотехнологичному, ни к ресурсосберегающему производствам. В действительности, представленная стратегия диверсификации в рамках ТОСЭР может решить вопросы устойчивого развития территории в краткосрочном периоде через создание рабочих мест на производствах заявившихся резидентов в рамках утвержденных видов экономической деятельности. Таким образом, задача опережающего экономического и связанного с ним социального развития не может быть решена в отрыве от разработки действительно прорывных стратегических направлений социально-экономического развития монопродуктовой территории.

В течение ряда последних лет Россия перешла к стратегическому планированию, и в 2014 г. был принят Федеральный закон «О стратегическом планировании в Российской Федерации». В его развитии реализуются другие стратегические документы: стратегии научно-технологического развития, государственной культурной политики, развития физической культуры и спорта, экологической безопасности, развития малого и среднего предпринимательства, а также стратегии развития здравоохранения, образования, энергетическая стратегия и т.д. В конце 2014 г. была утверждена «Инвестиционная стратегия Пермского края на период до 2017 года» [5], которая базировалась на ключе- вых стратегических документах РФ и Пермского края. На тот период были определены доминанты влияния на рост промышленности края: обрабатывающее производство, включая химическое, коксо- и нефтепродуктов, целлюлозно-бумажное, транспортных средств, электро-, электронного и оптического оборудования, а также добыча полезных ископаемых. Именно эти виды экономической деятельности были включены как основные в заявку ТОСЭР МО ЧГП. Согласно системе целей этой инвестиционной стратегии, увеличение объема вложений в экономику региона должно было составить $17,5 \%$, а количество вновь созданных, модернизированных рабочих мест увеличиться на 6 тыс. ед. Кроме того, число территориальных, инновационных, технологических кластеров в Пермском крае в период 2014-2017 гг. должно было составить 9 ед.

Данная стратегия, актуальная на досанкционный период и рассчитанная на сохранение и развитие международных торговых отношений, уже в 2015 г. требовала корректировки. Действительно, требовалось создание в крае значительно большего числа новых или модернизированных рабочих мест с учетом высвобождения только на одном ОАО «ЧМЗ» практически шести тыс. человек, не обеспеченных вновь созданными рабочими местами. Фактические значения показателя сокращенных, уволенных работников завода «закрывали» позицию целевого показателя по модернизированным и вновь созданным рабочим местам во всем Пермском крае.

Если обратиться к отраслевым приоритетам рассматриваемой стратегии Пермского края, то монопродуктовый регион Чусовской район указывается как основной по развитию и обновлению металлургической отрасли в регионе. Инновационное обновление возлагалось на Объединенную Металлургическую Компанию, сформировавшую на базе градообразующего предприятия структурную единицу ОМК «дивизион ЧМЗ» и планировавшую проведение технологической модернизации, замену производственных мощностей для повышения спроса на продукцию как на внутреннем, так и внешнем рынке. Данный проект считался крупнейшим в современной металлургии и был связан со строительством интегрированного трубно-сталеплавильного комплекса. К 2018 г. в моногороде Чусовой должны были функционировать электросталеплавильный цех, использоваться технологии непрерывной разливки стали, вступить в строй трубопрокатный цех. Отечественная экономика должна была получить бесшовные трубы большого диаметра для нефтегазового сектора категории «премиум», а также сортовой прокат и рессоры. Запланированные инвестиции в размере 50 млрд руб. были частично потрачены на подготовку производственных площадок под новый комплекс, проектно-сметную и рабочую документацию, подготовку и переобучение кадров и т.д. В 2018 г. в ЧМЗ функционирует рессорное, прокатное, ферросплавное производство со службами сервисных и вспомогательных цехов. Все остальные работы свернуты, проект по строительству трубно-сталеплавильного комплекса закрыт еще в 2015 г. 
Таким образом, социально-экономическая ситуация в старопромышленном моногороде Пермского края, несмотря на меры собственника градообразующего предприятия, государственной поддержки (софинансирование КИП 2010-2012 гг.), включение в инвестиционные программы края, выделение крупных инвестиций собственников и государственные гарантии, государственные инвестиции в социально-значимые проекты, экономическая ситуация в монопродуктовом регионе не улучшается. Именно поэтому особые надежды население связывает с проектом вхождения монопродуктового региона - Чусовское городское поселение - в ТОСЭР.

Таким образом, выбранная модель увязки развития монопродуктового района в соответствии с точками роста всего региона можно признать актуальной и для Чусовского муниципального района Пермского края. Но требуемый результат возможен не только в случае «увязки» стратегии развития всего региона и ЧМР, но и соответствия программы развития района как ТОР, территории опережающего развития, с ориентацией на конкурентные отрасли, конкурентные производства, неформальную диверсификацию экономики, ускоренное развитие бизнес-процессов, новую кадровую политику. Для этого автор предлагает проект концепции развития монопродуктового района с учетом вышеизложенных проблем и идей.

Концепция как документ стратегического планирования должна опираться на факторы внешней и внутренней среды. Актуальность этой группы факторов связана с продолжением и усилением негативных воздействий на отечественную экономику со стороны целого ряда стран, политические и экономические интересы которых находятся в противоречии с укреплением позиций России как политического игрока на внешнем контуре. Резкие и частые изменения внешней среды потребовали опережающих действий и выявления, быстрого развития конкурентных преимуществ. В случае моногородов, монопродуктовых районов факторы внешней среды первой группы факторов потребовали именно опережающего развития этих территорий, что в свою очередь потребовало эффективной городской, районной политики, новых подходов к управлению, менеджменту. Внутренние факторы включают такую подгруппу, как не вовлечение в процесс обсуждения планов стратегического развития населения территорий и формальный подход к подбору стейкхолдеров. Если последняя подгруппа факторов находится в поле компетенций местной администрации, то на факторы внешней среды она не может оказать влияния.

Однако к факторам внешней среды относится и специализация монопрофильного района в рамках региона, края. И если в стратегии края за районом определена функция металлургического локомотива, то резкий уход от отраслевого приоритета должен иметь альтернативы, обозначенные в стратегических документах края, что станет ориентиром для района. В настоящее время данные приоритеты не определены.

Предметом настоящей Концепции являются основные направления развития старопромышленных мо- нопродуктовых районов края на траекторию экономического роста через инновационные проекты как базу диверсификации экономики районов и городов данного типа. Актуальность выбора данной основы связана с необходимостью выхода на конкурентный уровень всей отечественной экономики, а не только незначительного ряда отраслей. В этом случае значительно возрастает действие таких факторов инновационного развития, как восприимчивость к инновациям и рост человеческого капитала во всех его структурных элементах.

Следующая группа факторов - факторы инновационного развития старопромышленных монопродуктовых районов и городов. Их действие связано привлечением и созданием на этих территориях промышленного комплекса с высокотехнологичными производствами. Неотделимой от нее является еще одна группа - факторы развития инновационной инфраструктуры. Актуализированные на текущий период технопарки, индустриальные парки, инновационные парки пришли на смену бизнес-инкубаторов, которые не смогли решить задачу резкого подъема предпринимательской активности в моногородах, особенно - с тяжелой социально-экономической ситуацией. По мнению автора, эти модели инфраструктуры должны быть расширены или «сшиты» через платформу развития инновационной инфраструктуры монопродуктовых районов региона, содержащей среди других элементов проектные офисы инновационного развития и предпринимательства, центры промышленных, технологических, управленческих, кадровых инноваций и т.д.

Важнейшая группа факторов, максимально содействующих опережающему развитию территории, содержит факторы обеспечения экономики монопродуктового района высокопрофессиональными кадрами, не только в областях диверсифицируемой экономики, но и в управленческой и социальной сфере, особенно - в образовании. Привлечение таких кадров может быть основано на идее «возвращения специалистов на малую родину» и компенсировать отток кадров градообразующего предприятия специалистами необходимого профиля и подготовки для реализации стратегии диверсификации моноэкономики. Группа факторов инфраструктуры генерации знаний, таким образом, содействует решению проблем привлечения, подготовки, переподготовки кадров для экономики территории опережающего развития.

Наконец, безусловно наибольшим влиянием для достижения цели опережающего развития монопродуктовой территории является реализация в рамках ТОСЭР модели стратегических инновационных сетей, более известной как модель тройной спирали. Данная модель инновационной системы характерна для рыночной экономики, и в условиях монопродуктовой экономики должны быть установлены соответствующие подходы через выявление особенностей процессов внедрения и распространения инноваций в условиях ее диверсификации.

Завершающая группа - факторы, способствующие формированию среды территории опережающего социально-экономического развития. 
Помимо факторного анализа, Концепция включает принципы, показатели и индикаторы развития экономики монопрофильных районов, отражающие суть смены парадигмы развития.

Концепция опережающего социально-экономического развития монопродуктового района содержит блок, включающий систему принципов, отражающих условия достижения целей ТОСЭР. Базовыми являются принцип связи инновационных процессов с рыночной необходимостью, опережающего развития инновационных подходов, инновационной лояльности, конкурентоспособности, прозрачности; баланса интересов акторов тройной спирали, комплексности, системности, инициативности, инновационной привлекательности муниципальных образований.

Опережающее развитие территории отражается в соответствующих числовых значениях показателей экономического роста и социального развития. В условиях экономики знаний именно инновации различного вида лежат в основе опережающего развития, следовательно, в качестве показателей целесообразно выделить следующие.

1. Число инновационных производств, открытых в монопродуктовом районе.

2. Число созданных в монопродуктовом районе организаций, включая сферу сервиса, применяющих инновационные продукты, технологии, методы.

3. Количество привлеченных на территорию монопродуктового района новшеств, инновационных технологий в сферах производства и жизнедеятельности.

4. Количество созданных в монопродуктовом районе инновационных продуктов, технологий в сферах производства и жизнедеятельности.

5. Количество внедренных на территории монопродуктового района продуктов, технологий в сферах производства и жизнедеятельности, созданных в этом монопродуктовом районе.

6. Количество представителей монопродуктового района, имеющих авторские свидетельства и патенты, участвующих в разработке, внедрении, коммерциализации инновационных идей, технологий, товаров, услуг.

7. Объем инвестиций, вложенных бизнесом монопродуктового района в разработку, внедрение, коммерциализацию инновационных идей, технологий, товаров, услуг.

8. Объем инвестиций, привлеченных в монопродуктовый район для разработки, внедрения, коммерциализации инновационных идей, технологий, товаров, услуг.

9. Число работников организаций, имеющих ученую степень / звание.

10. Число руководителей организаций, имеющих ученую степень / звание.

11. Число руководителей ТОСЭР, имеющих ученую степень / звание.

12. Число web-проектов в форме платформ инновационного развития, «сшивающих» элементы традиционной инновационной инфраструктуры инновационного (опережающего) территориального развития.

13. Количество участников web-проектов в форме платформ инновационного развития, «сшивающих» элементы традиционной инновационной инфраструк- туры инновационного (опережающего) территориального развития.

14. Число заключенных соглашений и совместных проектов в рамках платформы инновационного развития.

15. Уровень использования информационных технологий по видам экономической деятельности.

16. Уровень информатизации организаций и предприятий ТОСЭР.

17. Число образовательных курсов инновационной направленности, разработанных для населения и преподаваемых в дистанционном режиме.

18. Число курсов переподготовки кадров инновационной направленности в системе образования монопрофильного района для подготовки и переподготовки кадров.

19. Количество слушателей курсов инновационной направленности, разработанных для населения и преподаваемых в дистанционном режиме.

20. Количество слушателей курсов переподготовки инновационной направленности в системе образования монопрофильного района для подготовки и переподготовки кадров.

21. Число проектов поддержки бизнес-образования для дошкольного, школьного образования, средне-технического и высшего образования.

22. Количество участников проектов поддержки бизнес-образования для дошкольного, школьного образования, средне-технического и высшего образования.

23. Индекс человеческого развития (человеческого капитала).

24. Количество привлеченных специалистов высшей категории для реализации стратегии диверсификации моноэкономики старопромышленных монопродуктовых районов по проекту «возвращение специалистов на малую родину».

25. Количество партнерских соглашений в рамках модели тройной спирали.

26. Количество общественных слушаний в год по вопросам развития ТОСЭР в рамках конкретного монопродуктового района.

27. Число участников общественных слушаний в год по вопросам развития ТОСЭР в рамках конкретного монопродуктового района.

28. Число участников общественных слушаний, поддержавших предложения инициаторов по вопросам развития ТОСЭР в рамках конкретного монопродуктового района.

29. Количество СМИ ТОСЭР.

30. Количество публикаций СМИ ТОСЭР в месяц по проблемам и направлениям эффективной реализации проектов, программ и мероприятий ТОСЭР.

31. Число встреч администрации ТОСЭР с населением монопродуктового района по вопросам достижения целей и решения задач ТОСЭР этого монопродуктового района.

32. Количество участников (жителей) встреч администрации ТОСЭР с населением монопродуктового района по вопросам достижения целей и решения задач ТОСЭР этого монопродуктового района. 
33. Количество участников (жителей) встреч администрации ТОСЭР с населением монопродуктового района по вопросам достижения целей и решения задач ТОСЭР этого монопродуктового района, поддержавших (одобривших) деятельность органов власти.

Укажем некоторые индикаторы, которые отражают инновационный потенциал ТОСЭР, созданной в рамках монопродуктового района.

1. Для показателей уровня инновационного развития территории опережающего социально-экономического развития:

1.1. Индекс доли инновационно-активных организаций (разрабатывающих, внедряющих, производящих, применяющих свою инновационную продукцию, технологию) в общем числе организаций монопродуктового района.

1.2. Индекс доли инновационно-активного персонала организаций.

1.3. Индекс съема инновационной продукции с одной инновационно-активной организации монопродуктового района.
2. Для показателей инновационной лояльности акторов и институтов развития территории опережающего социально-экономического развития:

2.1. Уровень восприимчивости акторов монопродуктового района к внедрению инновационных технологий.

2.2. Уровень эффективности работы институтов развития по поддержке инновационного развития ТОСЭР.

2.3. Уровень реализации инновационной продукции организаций ТОСЭР в рамках монопродуктового района в общем объеме инновационной продукции (продукции с высокой добавленной стоимостью), реализованной на рынке ТОСЭР.

Данные индикаторы выбраны с учетом результатов исследований, проведенных в [6].

В заключение отметим, что проблемы выхода монопродуктовых районов Пермского края из кризисных ситуаций, характеризующихся в определенные периоды как риск депрессивности, были ранее исследованы автором в [7-10].

\title{
Литература
}

1. Ризов А. Д., Пастухов А. Л., Угольников В. В., Буряк Д. В., Тимощенко Е. А., Угольникова О. Д. Инновационное развитие старопромышленных моногородов: от идеи к реализации. СПб.: СПбГЭУ, 2016.77 с.

2. Об утверждении перечня монопрофильных муниципальных образований РФ (моногородов). Распоряжение правительства РФ от 29.07.2014 № 1398-p. Режим доступа: http://legalacts.ru/doc/rasporjazheniepravitelstva-rf-ot-29072014-n-1398-r/ (дата обращения: 06.01.2018).

3. О территориях опережающего социально-экономического развития в РФ. Федеральный закон № 473 от 29.12.2014. Режим доступа: http://www.consultant.ru/document/cons_doc_LAW_172962/(дата обращения: 06.01.2018).

4. Ризов А. Д. Особенности трансформации социально-экономических процессов в монопродуктовом регионе: проблемы и пути их решения: дис. ... канд. экон. наук; СПб гос. экон. ун-т. Санкт-Петербург, 2015.278 с.

5. Об утверждении Инвестиционной стратегии Пермского края на период до 2017 года. Постановление Правительства Пермского края № 1458-п от 15.12.2014. Режим доступа: http://economy.permkrai.ru/upload/ iblock/ace/Постановление\%20Правительства\%20Пермского\%20края.pdf (дата обращения: 07.01.2018).

6. Качество жизни и безопасность России / под ред. В. А. Черешнева, А. И. Татаркина. Екатеринбург: Институт экономики УрО РАН, 2009. 1184 с.

7. Ризов А. Д. Моделирование управления и прогнозирования социально-экономического развития депрессивных регионов // Дискуссия. 2014. № 4. С. 93-97.

8. Ризов А. Д. Старопромышленные моногорода: стратегии устойчивого развития в условиях инновационной экономики // Стратегия устойчивого развития регионов России: материалы тридцать третьей Всероссийской научно-практической конференции. Новосибирск, 2016. С. 40-45.

9. Ризов А. Д. Стратегический подход к управлению социально-экономическими процессами в моногородах // Вестник Самарского государственного экономического университета. 2014. № 4. С. 49-53.

10. Ризов А. Д. Типологические характеристики моногородов: концептуальный аспект // Теория и практика общественного развития. 2014. № 10. Режим доступа: http://teoria-practica.ru/ (дата обращения: 07.01.2018).

\section{DEVELOPMENT OF THE PRIORITY SOCIAL AND ECONOMIC DEVELOPMENT AREAS WITHIN THE BOUNDARIES OF THE OLD INDUSTRIAL MONOCITIES Alexey D. Rizovi, 2,}

\author{
${ }^{1}$ Joint Stock Company "Chusovskoy Metallurgical Plant", 13, Trudovaya St., Chusovoy, Russia, 618200 \\ ${ }^{2}$ Zemsky Assembly of Chusovsky Municipal District, 8B, Sivkova St., Chusovoy, Russia, 618204 \\ @aleksejrizov@rambler.ru
}


Keywords: old industrial monocities, monoproduct region, innovative strategy, Priority Social and Economic Development Areas.

\begin{abstract}
The subject of the current research is the old industrial monocities and monoproduct regions of the Perm region. The goal is the development of strategic approaches to solving the scientific and practical problem of realizing the prospects of Priority Social and Economic Development Areas, created within the boundaries of mono-product regions. The methodology of work is based on N.D. Kondratiev's wave theory, G. Mensch's concept of innovation activity, M. Porter's concept of clusters, the concept of triple helix, etc.

Its basis is the concept of innovative development of old industrial monocities [1]. The research results can assist monoproduct regions in obtaining the Priority Social and Economic Development Area status. Also, the area of application of the results includes mono-product regions that have already obtained the status in question.

The author concludes that application for the status should be preceded by a scientifically sound strategy for the development of mono-product regions, which has received the support of the local population.
\end{abstract}

For citation: Rizov A. D. Razvitie TOSER v granitsakh staropromyshlennykh monogorodov [Development of the Tased Within the Boundaries of the Old Industrial Monocities]. Bulletin of Kemerovo State University. Series: Political, Sociological and Economic Sciences, no. 2 (2018): 133-138. DOI:10.21603/2500-3372-2018-2-133-138.

\title{
References
}

1. Rizov A. D., Pastukhov A. L., Ugolnikov V. V., Buriak D. V., Timoshenko, E. A., Ugolnikova O. D. Innovatsionnoe razvitie staropromyshlennykh monogorodov: ot idei k realizatsii [Innovative development of old industrial monocities: from idea to realization]. Saint-Petersburg: SPbGEU, 2016, 77.

2. Ob utverzhdenii perechnia monoprofil'nykh munitsipal'nykh obrazovanii RF (monogorodov) [On approval of the list of monoprofile municipal formations of the Russian Federation (monotowns)]. The order of the government of the Russian Federation No. 1398-r of 29.07.2014. Available at: http://legalacts.ru/doc/rasporjazhenie-pravitelstvarf-ot-29072014-n-1398-r/ (accessed 06.01.2018).

3. O territoriiakh operezhaiushchego sotsial'no-e konomicheskogo razvitiia v RF. [On the territories of advanced social and economic development in the Russian Federation]. Federal Law No. 473 of December 29, 2014. Available at: http://www.consultant.ru/document/cons_doc_LAW_172962/ (accessed 06.01.2018).

4. Rizov A. D. Osobennosti transformatsii sotsial'no-ekonomicheskikh protsessov v monoproduktovom regione: problemy i puti ikh resheniia. Diss. kand. ekon. nauk [Peculiarities of transformation of socio-economic processes in a single-product region: problems and ways to solve them. Cand. econ. Sci. Diss.]. St.-Petersburg State econ. Univ., St.-Petersburg, 2015, 278.

5. Ob utverzhdenii Investitsionnoi strategii Permskogo kraia na period do 2017 goda [On approval of the Investment Strategy of the Perm Krai for the period until 2017]. Decree of the Government of the Perm Krai No. 1458-p of December 15, 2014. Available at: http://economy.permkrai.ru/upload/iblock/ace/Постановление\%20 Правительства\%20Пермского\%20края.pdf (accessed 07.01.2018).

6. Kachestvo zhizni i bezopasnost' Rossii [Quality of life and security in Russia]. Ed. Chereshnev V. A., Tatarkin A. I. Ekaterinburg: UrO RAN, 2009, 1184.

7. Rizov A. D. Modelirovanie upravleniia i prognozirovaniia sotsial'no-ekonomicheskogo razvitiia depressivnykh regionov [Modeling of management and forecasting for social and economic development of depressed regions]. Diskussiia = Discussion, no. 4. (2014): 93-97.

8. Rizov A. D. Staropromyshlennye monogoroda: strategii ustoichivogo razvitiia v usloviiakh innovatsionnoi ekonomiki [Old-industry monocities: sustainable development strategies in an innovative economy]. Strategiia ustoichivogo razvitiia regionov Rossii: materialy 33 Vserossiiskoi nauchno-prakticheskoi konferehtsii [Strategy of sustainable development of Russian regions: Proc. 33th All-Russian Sc.-Prac. Conf.]. Novosibirsk, 2016, 40-45.

9. Rizov A. D. Strategicheskii podkhod k upravleniiu sotsial'no-e konomicheskimi protsessami v monogoradakh [Strategic approach to managing socio-economic processes in single-industry towns]. Vestnik Samarskogo gosudarstvennogo ekonomicheskogo universiteta = Bulletin of Samara State University, no. 4 (2014): 49-53.

10. Rizov A. D. Tipologicheskie kharakteristiki monogorodov: kontseptual'nyi aspect [Typological characteristics of single-industry towns: the conceptual aspect]. Teoriia I praktika obshchestvennogo razvitiia $=$ Theory and practice of social development, no. 10 (2014). Available at: http://teoria-practica.ru/ (accessed 07.01.2018). 